\title{
Ground-based detection of sprites and their parent lightning flashes over Africa during the 2006 AMMA campaign
}

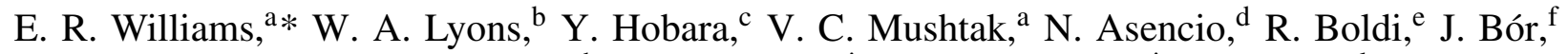 \\ S. A. Cummer, ${ }^{\mathrm{g}}$ E. Greenberg, ${ }^{\mathrm{h}}$ M. Hayakawa, ${ }^{\mathrm{i}}$ R. H. Holzworth, ${ }^{\mathrm{j}}$ V. Kotroni, ${ }^{\mathrm{k}} \mathrm{J}$. Li, ${ }^{\mathrm{g}}$ \\ C. Morales, ${ }^{1}$ T. E. Nelson, ${ }^{\mathrm{b}}$ C. Price, ${ }^{\mathrm{h}}$ B. Russell, ${ }^{\mathrm{m}}$ M. Sato, ${ }^{\mathrm{n}}$ G. Sátori, ${ }^{\mathrm{f}}$ K. Shirahata, ${ }^{\mathrm{c}}$ \\ Y. Takahashi ${ }^{\mathrm{O}}$ and K. Yamashita ${ }^{\mathrm{O}}$ \\ ${ }^{a}$ Parsons Laboratory, Massachusetts Institute of Technology, Cambridge, Massachusetts, USA \\ ${ }^{\mathrm{b}}$ FMA Research, Inc., Fort Collins, Colorado, USA

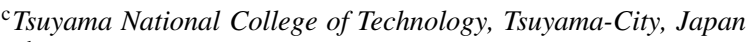 \\ ${ }^{\mathrm{d}}$ CNRM-GAME, Météo-France and CNRS, Toulouse, France \\ ${ }^{\mathrm{e}}$ University of Alabama, Huntsville, Alabama, USA \\ ${ }^{\mathrm{f}}$ Geodetic and Geophysical Research Institute, Hungarian Academy of Sciences, Sopron, Hungary \\ ${ }^{\mathrm{g}}$ Duke University, Durham, North Carolina, USA \\ ${ }^{\mathrm{h}}$ University of Tel Aviv, Tel Aviv, Israel \\ ${ }^{\mathrm{i}}$ University of Electro-Communications, Chofu, Tokyo, Japan \\ $\mathrm{j}$ University of Washington, Seattle, Washington, USA \\ ${ }^{\mathrm{k}}$ National Observatory of Athens, Athens, Greece \\ ${ }^{1}$ University of Sao Paulo, Sao Paulo, Brazil \\ ${ }^{\mathrm{m}}$ University of Michigan, Ann Arbor, Michigan, USA \\ ${ }^{\mathrm{n}}$ Hokkaido University, Japan \\ ${ }^{\circ}$ Tohoku University, Japan
}

\begin{abstract}
Sprites have been detected in video camera observations from Niger over mesoscale convective systems in Nigeria during the 2006 AMMA (African Monsoon Multidisciplinary Analysis) campaign. The parent lightning flashes have been detected by multiple Extremely Low Frequency (ELF) receiving stations worldwide. The recorded charge moments of the parent lightning flashes are often in excellent agreement between different receiving sites, and are furthermore consistent with conventional dielectric breakdown in the mesosphere as the origin of the sprites. Analysis of the polarization of the horizontal magnetic field at the distant receivers provides evidence that the departure from linear magnetic polarization at ELF is caused primarily by the day-night asymmetry of the Earth-ionosphere cavity. Copyright (C) 2009 Royal Meteorological Society
\end{abstract}

KEY WORDS Q-burst; ELF; Lissajous; day-night asymmetry; sprite; mesoscale convective system

Received 11 December 2008; Revised 3 July 2009; Accepted 8 July 2009

\section{Introduction}

This study is concerned with the ground-based detection of sprites over the African continent, and with the detection of their parent lightning flashes from multiple electromagnetic receivers over the globe. Among the three tropical 'chimneys' of prominent lightning activity, Africa is the last to come under scrutiny by surface instruments because of infrastructural limitations, and so has remained to a large extent the 'dark continent'. Recent innovation in the African Monsoon Multidisciplinary Analysis (AMMA) (Redelsperger et al., 2006) has thrown important new light on the darkness.

Much is known about thunderstorm activity in Africa on the basis of remote sensing with both satellite and

\footnotetext{
*Correspondence to: E. R. Williams, Parsons Laboratory, Massachusetts Institute of Technology, Cambridge, Massachusetts, USA.

E-mail: earlew@1l.mit.edu
}

electromagnetic methods, and many previous observations support the idea that sprites would occur with great abundance there (Füllekrug and Price, 2002; Chen et al., 2008). Optical observations of lightning with the Optical Transient Detector (OTD) and the Lightning Imaging Sensor (LIS) have established Africa as the tropical 'hot spot' for lightning (Christian et al., 2003; Williams and Sátori, 2004). In reviewing the meteorological conditions favourable for Transient Luminous Event (TLE)-producing lightning discharges, Lyons (2006) has noted that sprites and halos are most frequently observed above large mesoscale convective systems (MCSs), and in particular those with expansive stratiform precipitation regions (Lyons et al., 2003). Laing and Fritsch (1993) documented the frequent occurrence of expansive, longlived mesoscale convective complexes over the African Sahel, and to a lesser extent over the equatorial rain forests and southern Africa. Toracinta and Zipser (2001) 
have identified Africa in satellite observations as the most exceptional tropical region in the category of MCSs with exceptionally low cloud-top temperatures. All of the foregoing storm observations are favourable to the sprite requirement for superlative lightning events, with 'mesoscale' characteristics (Boccippio et al., 1995; Williams and Yair, 2006).

Storms with exceptional size are also called into play by the electrostatic requirement for sprites, set forth by the prescience of C.T.R. Wilson (1924) and refined by numerous recent studies (Boccippio et al., 1995; Cummer and Inan, 1997; Huang et al., 1999; Williams, 2001; Hu et al., 2002; Cummer and Lyons, 2005). The electrostatic mechanism for sprite initiation involves an exceptional vertical charge moment change in the parent lightning flash. These charge moments are established in observations primarily by remote sensing in the extremely low frequency (ELF) electromagnetic range, with global reach from single receivers (Huang et al., 1999; Hobara et al., 2006; Williams et al., 2007b). Similar to the situation for ordinary lightning flashes, Africa is also predominant in events with exceptional charge moment (Hobara et al., 2006; Williams et al., 2007a). The present study continues with the use of ELF methods for event characterization.

Given the abundance of MCS activity over Africa, perhaps it is not too surprising that probably the earliest reference clearly describing a sprite over Africa was published by D.F. Malan, who made naked eye observations of sprites above a distant South African MCS, noting 'a long and faint streamer of reddish hue... some $50 \mathrm{~km}$ high' (Malan, 1937). Lyons and Williams (1993) reported on detailed analyses of low-light television (LLTV) video of lightning-related phenomena taken aboard the Space Shuttle during missions from 1989 to 1991 (Boeck et al., 1995). It was noted that the TLEs (almost all sprites) tended to occur above large MCSs though not necessarily in the portion of the storm with the highest flash rates. Four of 14 events inspected by Lyons and Williams (1993) occurred over the African continent. Among the first African sprite observations reported from the Space Shuttle LLTV examined by Vaughan et al. (1992) were those found over Mauritania $\left(\sim 7.5^{\circ} \mathrm{N}, \sim 4.0^{\circ} \mathrm{E}\right)$ on 28 April 1990. Sprite activity over the Congo basin of the African continent was confirmed in Space Shuttle observations during the MEIDEX (Mediterranean Israeli Dust Experiment) mission in January 2003 (Yair et al., 2004).

Prior to the observations reported in this paper, however, no terrestrial camera had recorded a TLE above an African storm. The energetic parent lightning flashes for these African sprite events were also detected electromagnetically by an unprecedented total number of VLF networks (two) and ELF receivers (six), as summarized in Table I.

\section{Methodology}

The establishment of observations for sprite detection over Africa was piggy-backed on a project to operate the Massachusetts Institute of Technology (MIT) C-band Doppler radar for AMMA in Niamey, Niger $\left(13.5^{\circ} \mathrm{N}\right.$ $2.2^{\circ} \mathrm{E}$ ). The selection of Niamey international airport for radar operation also afforded opportunities for video camera operation.

\subsection{Video camera observations}

A portable low-light television (LLTV) camera system was assembled and transported to Niamey. Video was acquired using a Watec LCL-902K unit, a non-intensified half inch charge-coupled device (CCD) with 0.00015 lux sensitivity and 570 lines resolution. Optics employed were an f/0.8 Computar $6 \mathrm{~mm}$ lens ( $\sim 55$ degree horizontal field of view). The tripod-mounted unit could be easily deployed with power supplied by a $12 \mathrm{~V}$ automotive battery and inverter. Video time stamping to the millisecond was applied to each field of video using a KIWI-OSDRTD unit from PFD Systems, and a Garmin Model 18LVC Global Positioning System (GPS) receiver. Video was written to an S-VHS video cassette recorder.

Initial attempts to operate the camera in the main control tower were thwarted by local runway illumination and building lights. The camera and recording equipment was subsequently moved to a smaller tower on the east end of the east-west-oriented main runway, remote from both the main control tower and the lights of the city of Niamey located west of the airport, and where dark conditions prevailed facing east. Fortuitously, the most prevalent direction of MCS/squall-line approach to Niamey was also from the dark eastern sector.

\subsection{Satellite observations}

Meteosat satellite imagery available in real time at both the MIT radar site and at the ASECNA (Agency for Air Safety in Africa and Madagascar) forecast office in the main airport building in Niamey was used to document the occurrence of mesoscale convective systems over West Africa and to make decisions in late afternoon about the value of late evening observations with the video camera. These satellite data were also archived by Météo-France for AMMA with 30 minute resolution, from which movies of the MCS evolution were produced, as a forecasting tool. In general, the MCS 'targets of opportunity' for the video camera observations developed in central and eastern Niger, and in northern Nigeria. In the majority of cases, however, the observations of sprites were spoiled by the advection of upper-level cirrus cloud into the Niamey area, thereby blocking our view of the mesosphere over MCSs further east. The nights of 30 August and 21 September 2006 were special exceptions, and the Meteosat imagery described below documents that well.

\subsection{Remote ELF observations}

The strong electromagnetic radiation from the lightning discharges responsible for sprites in the mesosphere is radiated globally in the ELF region. For the African sprites documented in this study with the video camera, 


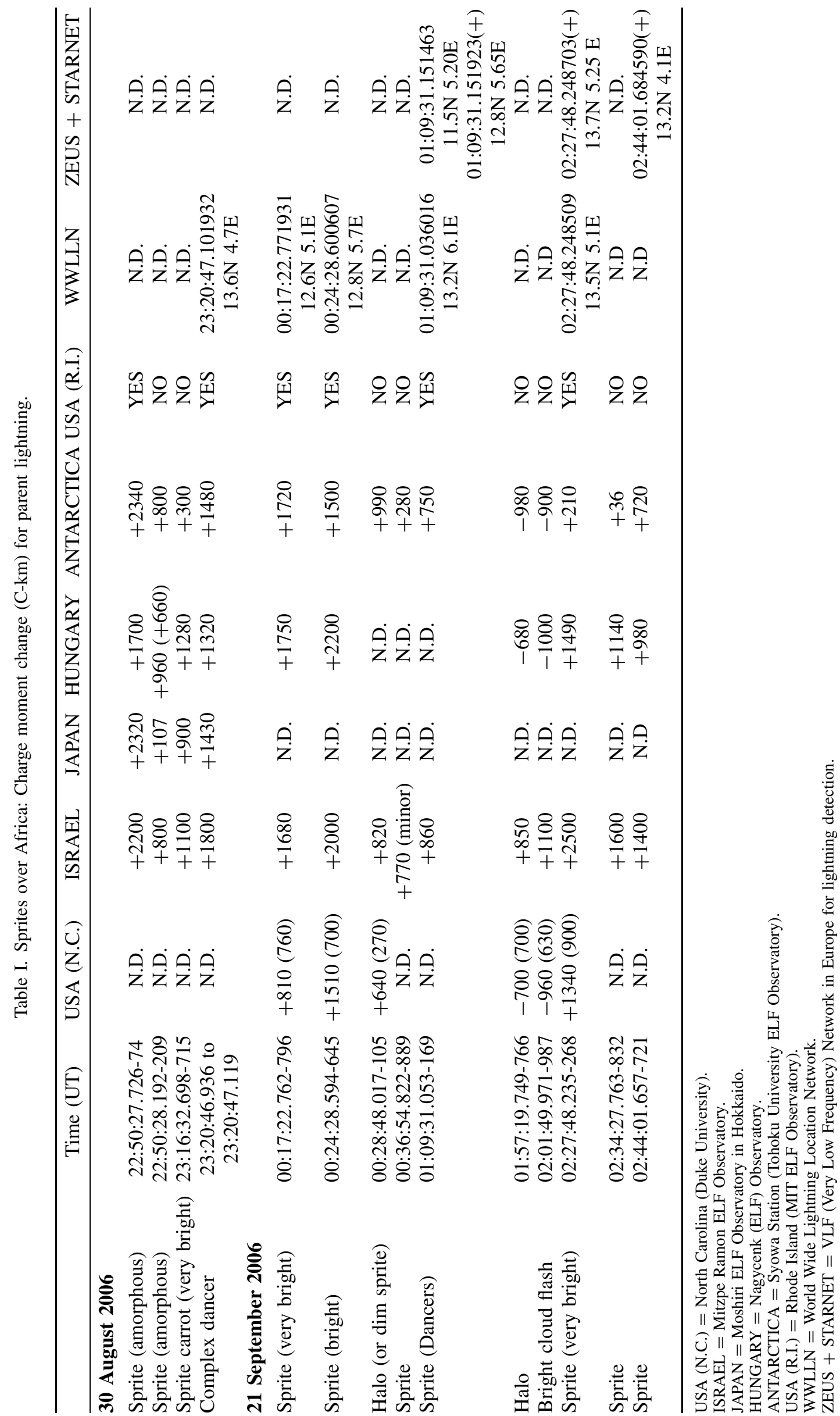


these signals were detected by six separate ELF receivers, in Antarctica, Hungary, Israel, Japan and two within the United States. The vertical charge moment change of the causative lightning could be evaluated on the basis of these separate observations, and can be compared. Furthermore, the reception of signals by multiple stations has enabled a comparison between theory and observation on the polarization behaviour of the ELF magnetic field. A brief description of the ELF receiver sites and their data-processing methods follows below.

\subsubsection{Duke University (USA)}

The Duke University sensors used here are located at a field site near the university $\left(35.98^{\circ} \mathrm{N}, 79.10^{\circ} \mathrm{W}\right)$. The data presented here were recorded with two EMI BF-4 magnetic field coils $(<0.1$ to $500 \mathrm{~Hz}$ bandwidth, sampled continuously at $2.5 \mathrm{kHz}$ ) to provide the full horizontal vector magnetic field. GPS provides absolute timing accuracy.

In our quantitative analysis we combine finite difference propagation simulations (Cummer and Inan, 1997) and a deconvolution approach (Cummer and Inan, 2000) to extract a full current moment wave-form of the first $80 \mathrm{~ms}$ of the discharge from the directly propagating portion of the recorded signal (i.e. the around-the-world components are neglected). Given the long propagation distance $(\sim 8000 \mathrm{~km})$ of the direct signal, which filters out much of the lightning signal above $200 \mathrm{~Hz}$, our time resolution in this analysis is approximately $5 \mathrm{~ms}$. Thus, for summary purposes, the $80 \mathrm{~ms}$ charge moment change is computed from our current moment wave-forms, and is dominated by the return stroke and any short-duration continuing current. The $80 \mathrm{~ms}$ charge moment change includes any significant long-duration continuing current as well.

The analysis here has been cross-checked by computing an expected Schumann resonance wave-form from our extracted current moment wave-form using the model of Huang et al. (1999). In all cases the $80 \mathrm{~ms}$ duration current moment wave-form was consistent (given the background noise) with the around-the-world signals, indicating that the $80 \mathrm{~ms}$ charge moment change is our best estimate of that for the entire flash.

\subsubsection{ELF observation system in Mitzpe-Ramon, Israel}

The ELF instruments in Israel are located at Tel Aviv University's Wise astronomical observatory near the town of Mitzpe-Ramon (MR) in the Negev Desert $\left(30.6^{\circ} \mathrm{N}\right.$, $34.8^{\circ} \mathrm{E}$ ). This remote area which has much-reduced anthropogenic electromagnetic noise levels is located far from industrial activity which produces different kinds of ELF interferences (50 Hz power supply lines) contaminating the signal. The station has two horizontal magnetic induction coils for receiving the magnetic field, one in the north-south direction $\left(H_{\mathrm{NS}}\right)$ and one in the east-west direction $\left(H_{\mathrm{EW}}\right)$ and one ball antenna for receiving $E_{r}$. The three electromagnetic field components are sampled at $250 \mathrm{~Hz}$ using a 16-bit $\mathrm{A} / \mathrm{D}$ converter.
A notch filter at $50 \mathrm{~Hz}$ is used to remove the most offensive power line harmonic. The raw time-series data are saved in 5-minute files, controlled and monitored via PC-Anywhere, with all analysis performed during post-processing. The system uses accurate GPS timing for temporally correlating with other electromagnetic and optical instruments involved with the AMMA project.

\subsubsection{ELF receiver in Moshiri (Japan)}

The ELF electromagnetic field has been continuously monitored in Moshiri (MSR) station, Hokkaido, Japan $\left(44.2^{\circ} \mathrm{N}, 142.2^{\circ} \mathrm{E}\right)$ operated by the University of ElectroCommunications since 1996 (Hobara et al., 2000, 2001), and the whole ELF system was upgraded in 2005 (Ando et al., 2005). Moshiri Observatory is considered to be one of the electromagnetically quietest places in Japan. Two horizontal magnetic fields are measured by orthogonally oriented induction search coils, aligned with geographical north and east, respectively. The vertical electric field is observed with a capacitor-type antenna. These antenna systems are fully calibrated and sampled at the frequency of $4000 \mathrm{~Hz}$ with a pass-band of $1 \mathrm{kHz}$, so that the wave-forms of ELF signals (Schumann resonances, ELF transients, etc.) are continuously recorded for any further analysis. A GPS receiver provides an absolute time stamp for each sampling point.

\subsubsection{Schumann resonance (SR) station in Nagycenk (Hungary)}

The SR station at Nagycenk Observatory (NCK; $47.62^{\circ} \mathrm{N}$, $16.72^{\circ} \mathrm{E}$ ) was established in 1993 starting with the quasi-real time determination of the spectral parameters (peak frequency, amplitude) of the vertical electric field component, $E_{r}$ (Sátori et al., 1996). The SR recording system was completed with the measurement of the two horizontal magnetic field components $\left(H_{\mathrm{NS}}\right.$ and $\left.H_{\mathrm{EW}}\right)$.

The onset of a detected SR transient is considered when the gradient of the signal in the $E_{z}$ field component exceeds a threshold. TLE-associated SR transients are found by matching the transient onset times with the optical observation times. The polarity of the parent stroke can be determined from $E_{z}$ and the location and charge moment changes can be deduced together from the electric, $E_{z}$, and the magnetic components, $H_{\mathrm{NS}}$ and $H_{\text {EW }}$ (Huang et al., 1999).

\subsubsection{ELF station operated in West Greenwich, Rhode} Island (USA)

MIT has operated ELF receiving equipment on the Alton Jones Campus of the University of Rhode Island in West Greenwich since 1993. Recording procedure and instrument details for background (Heckman et al., 1998) and transient (Huang et al., 1999) Schumann resonance observations have appeared in earlier publications. Threecomponent field measurements are normally in place, but during the AMMA campaign in summer 2006, the vertical electric channel was disabled by local lightning and so the usual wave impedance calculations for event characterization were not possible. 


\subsubsection{ELF receivers operated by Tohoku University (Antarctica)}

Tohoku University currently operates Schumann resonance receiving sites in Onagawa in Japan, Esrange in Sweden and Syowa station in Antarctica. For this study, the events of interest were captured only at Syowa station $\left(69.018^{\circ} \mathrm{S}, 39.506^{\circ} \mathrm{E}\right)$ in Antarctica. For procedure at Syowa, first the candidate events for the Q-burst of the parent lightning are selected by considering the propagation time-lag between Niamey and Syowa station. In the case that multiple bursts are detected, the initial peak is selected as the candidate for the parent stroke. Then the magnetic Lissajous figure for the event is examined to verify consistency with the signal generated by the propagation direction from Niamey. Finally the charge moment change is estimated according to the method shown in section 2.6.3 of Huang et al. (1999).

\subsection{VLF network observations}

\subsubsection{World Wide Lightning Location Network (WWLLN)}

The WWLLN uses long-range radio reception in the part of the VLF band ( 1 to $24 \mathrm{kHz}$ ) which includes the peak power from lightning ( 7 to $15 \mathrm{kHz}$ ). These waves travel long distances ( 6 to $10 \mathrm{Mm}$ ), allowing the entire globe to be monitored with just 28 WWLLN receiving stations (Lay et al., 2007). The lightning detection efficiency of WWLLN has been studied by several authors (cf. Jacobson et al., 2006; Rodger et al., 2006; Lay et al., 2007; Dowden et al., 2008; Lyons et al., 2009) in which it has been estimated that WWLLN detects lightning with a time error of $<30$ microseconds and a spatial location error of about $15 \mathrm{~km}$, even in areas for which no WWLLN stations are nearby. These studies have shown that WWLLN detects lightning strokes with peak currents $>50 \mathrm{kA}$, and is therefore useful for these TLE studies, where large peak currents are usually correlated with the probability of occurrence of TLEs (Lyons et al., 1996). The parent lightning flashes for five of the fourteen sprite events are included in Table I. The WWLLN global detection efficiency is only a few percent of total lightning, but typically over $20 \%$ for studies like the current one (4 of 14) and another study of TLEs in South America (Taylor et al., 2008).

\subsubsection{ZEUS + STARNET long range detection network}

Both ZEUS and STARNET long-rate lightning detection networks use the same technology developed by Resolution Displays Inc. (Morales, 2001). The system is composed of VLF $(7-15 \mathrm{kHz})$ antennas that detect the radio noise emitted by atmospheric discharges, known as 'sferics'. The VLF antennas record continuously the vertical electric field (waveforms) that propagates in the Earthionosphere waveguide. The waveforms are pre-amplified and time stamped with the GPS time $(1$ microsecond accuracy) at the receiver site and later encoded in an analog-to-digital converter. Furthermore, the digital data are sent to a central station that uncompresses the data. An identification algorithm excludes weak signal and noise data and is capable of capturing up to 70 sferics per second. At the central station the waveforms observed at the different VLF receivers are compared to extract the Arrival Time Difference (ATD), according to the methodology in Lee (1986a,b). In this comparison, the 4.5 millisecond waveforms from the two receivers are analyzed and the time lag with the highest cross-correlation values defines an ATD. Accordingly, ATD values represent positions between two outstations with the same time difference, and their intersection defines a sferics fix. The current location algorithm requires a minimum of four and a maximum of 30 receivers to record a single lightning event (Chronis and Anagnostou, 2003, 2006; Morales et al., 2007; Kotroni and Lagouvardos, 2008). The ZEUS network is composed of six receivers: Birmingham (UK), Roskilde (Denmark), Iasi (Romania), Larnaka (Cyprus), Athens (Greece) and Lisbon (Portugal). STARNET comprises another seven stations located in Addis Ababa (Ethiopia), Dar es Sallam (Tanzania), Bethlehem (South Africa), Osum State (Nigeria), Guadeloupe Island (Caribbean), and Fortaleza and Sao Paulo (Brazil). The ZEUS location accuracy within Europe was estimated to be of the order of $6 \mathrm{~km}$ (Lagouvardos et al., 2008) when compared with the LINET network (Betz et al., 2004). Over the African continent, Chronis and Anagnostou (2003, 2006) combined the African receivers of STARNET and ZEUS and have found a location accuracy of $\sim 20 \mathrm{~km}$. For this study, the two networks were integrated to locate accurately the sprite lightning parents, and in addition the polarity of the return stroke, inlucded in Table 1 (Morales et al., 2007).

\section{Results}

Sprites were documented in video camera imagery on two nights, 30 August and 21 September 2006. A summary of all 14 events, together with the independent electromagnetic documentation of the parent lightning flashes by remote ELF and VLF receivers, is shown in Table I. Consistent with earlier studies (Williams et al., 2007a), all of the events identified as sprites in the video camera observations (two left-hand columns) are associated with vertical charge moments with positive polarity and hence with positive ground flashes. One halo event however on 21 September 2006 is identified as having negative polarity for the majority of receiving stations. The seventh event on 21 September is labelled a 'bright cloud flash', and may not be a TLE at all, but just a bright lightning flash. Its polarity is also judged to be negative by most receivers. Specific documentation of conditions on the two separate nights is discussed in turn below.

\subsection{MCS on 30 August 2006}

A large isolated MCS was noted in Meteosat imagery $300 \mathrm{~km}$ east of Niamey. The video camera was set up by 


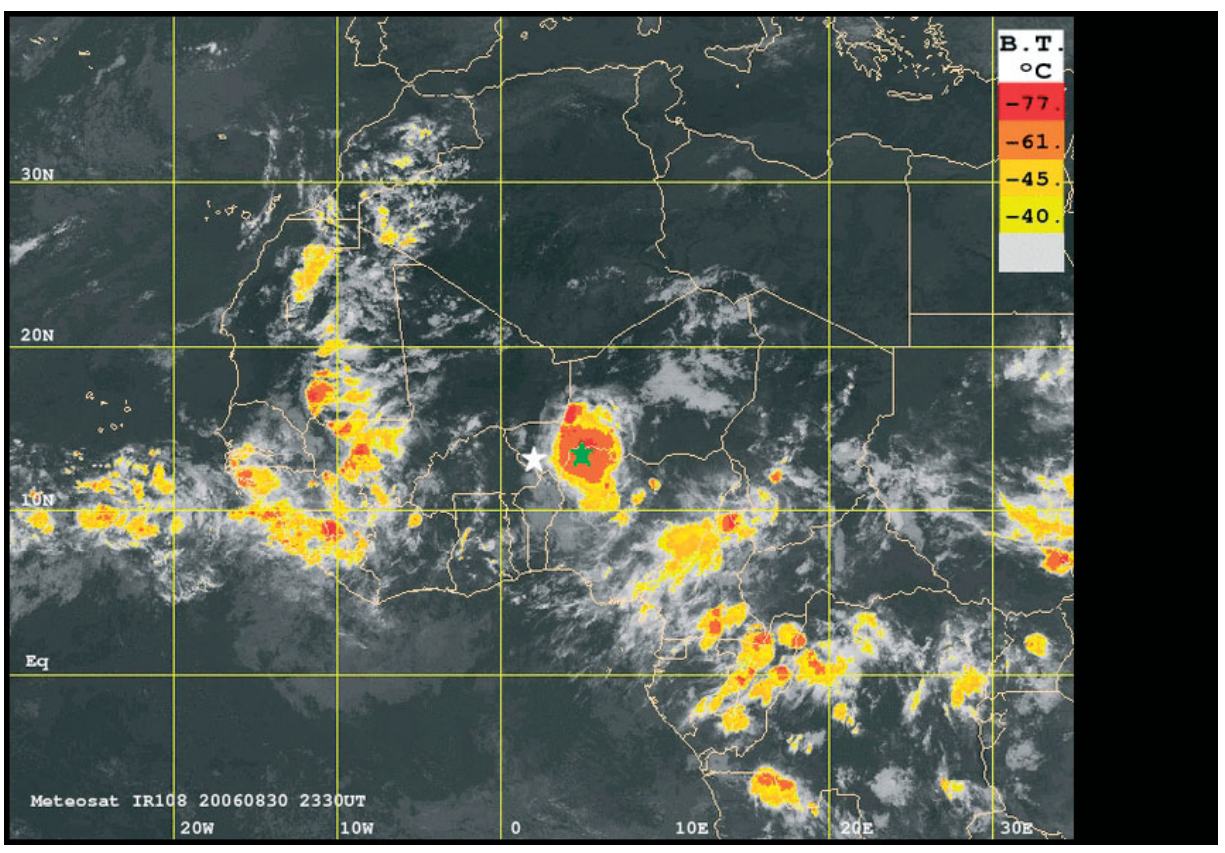

Figure 1. Meteosat imagery for 23:30 UT on 30 August 2006 showing large MCS east of Niamey, and the location (green star) of the parent cloud-to-ground lightning flash for the sprite at 23:20:47.101932 UT determined by the WWLLN. The white star shows the video camera location in Niamey, Niger.

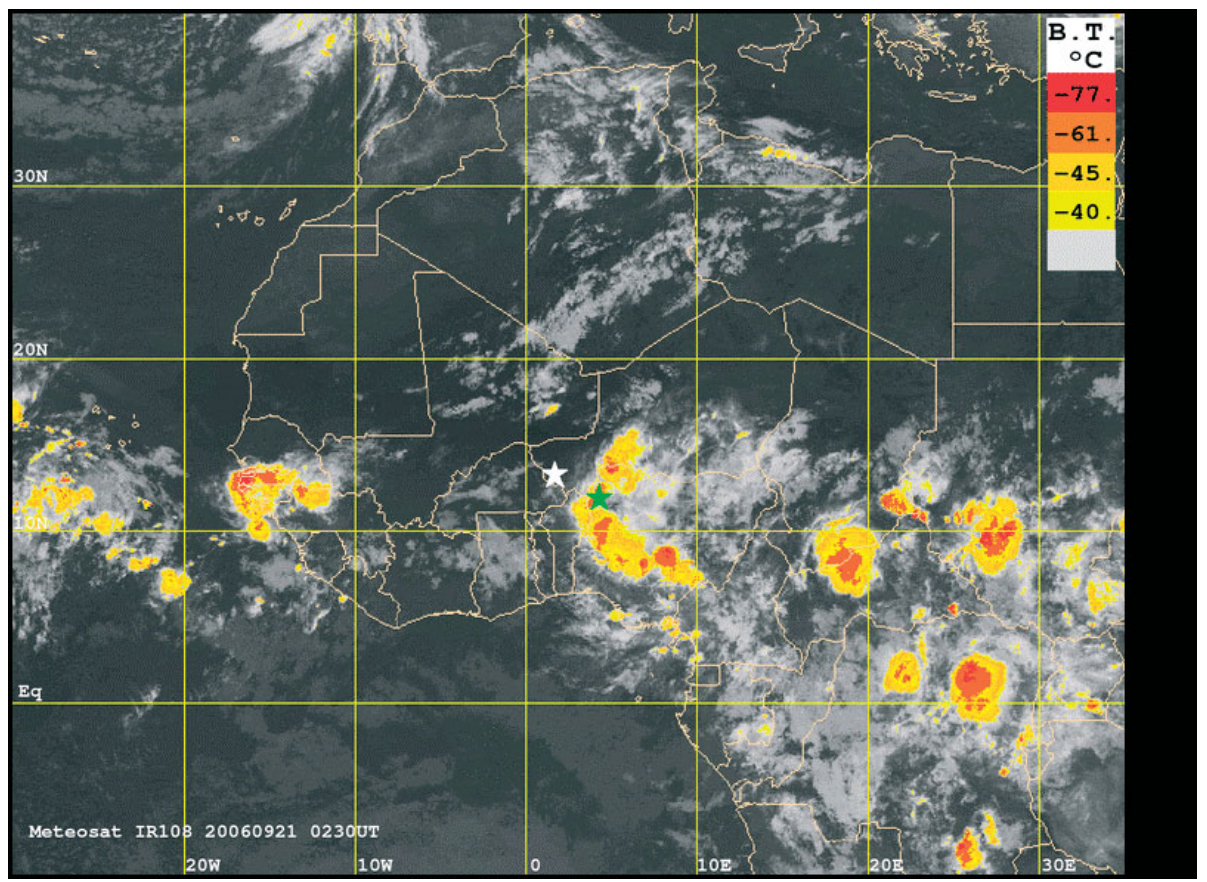

Figure 2. Meteosat imagery for 21 September 2006 at 02:30 UT nearest the time of the sprite observed from Niamey at 02:27:48.235 UT. The green star shows the location of the parent ground flash located by the VLF networks WWLLN and ZEUS + STARNET, whose location estimates are within about $20 \mathrm{~km}$ of each other (and small compared to the size of the star). The white star shows the video camera location at Niamey.

2240 UT, with a camera azimuth angle of 85 degrees, and a faint sprite was noted in the monitor in real time. (This was the only such event during the entire programme.) Four sprites in total were detected on the video tape in the interval 2250-2320 UT during playback after the field programme, and their GPS times are included in Table I.

Visual observations during this period of sprite observations showed a complete absence of stars below about
20-30 degree elevation from the horizon, attributable to the mineral dust typical of the West African Sahel. Diffuse flashes of light from distant lightning were noted in the east, with rates of 1-2 per minute.

A Meteosat image at 23:30 UT is shown in Figure 1. The large quasi-circular MCS east of Niamey is clearly evident, with cloud-top temperature $<-65^{\circ} \mathrm{C}$ indicated by the orange coloration. Based on MCS-Tracking 
analysis (Morel and Senesi, 2002; Tomasini et al., 2006), this MCS is growing at this time, with a minimum cloud-top temperature of $-82^{\circ} \mathrm{C}$. The green star indicates the position of the parent cloud-to-ground lightning determined by the WWLLN for the sprite event at 23:20:47.101932 UT. The location is consistent with the idea originating in earlier studies (Boccippio et al., 1995; Williams, 1998; Lyons et al., 2003; Williams and Yair, 2006) that the parent discharge lies in the trailing stratiform region of a squall line propagating westward toward the camera observation site in Niamey.

\subsection{Clustered MCSs on 21 September 2006}

Viewing conditions generally improved through the wet season in Niamey (July-September), consistent with the gradual decline in both total condensation nuclei and cloud condensation nuclei documented at the nearby ARM (Atmospheric Radiation Measurement) site (Miller and Slingo, 2007) at Niamey airport (data not shown). By this date, the viewing conditions were as good as they had ever been, and stars were visible in the monitor, with a note that no stars were visible below $10-20^{\circ}$ elevation angle from the horizon. The video camera was set up for logging by 2345 UT on 20 September 2006. At 0035 UT the camera was pointing east $\left(90^{\circ}\right.$ azimuth), and very dim, diffuse flashes of light from distant lightning were noted. Figure 2 shows a Meteosat image for 02:30 UT showing a bowed squall-line MCS $400 \mathrm{~km}$ east of Niamey with a north-south orientation. According to the MCSTracking analysis (Morel and Senesi, 2002; Tomasini et al., 2006), this MCS is growing, with a minimum cloud-top temperature of $-81^{\circ} \mathrm{C}$.

Ten sprites were noted in the camera imagery during replay following the field programme, in the 2.5 hour interval 0015-0245 UT (21 September 2006), as indicated in Table I. The green star in Figure 2 shows the location of the parent lightning of the sprite event at 02:27:48.235 UT, as determined by both the WWLLN and the ZEUS + STARNET VLF networks. (The time of this event agreed within 200 microseconds between the two networks, and the location by $20 \mathrm{~km}$.). Figure 3 shows a video camera image of the very bright sprite produced by this energetic lightning flash.

\subsection{Comparisons of charge moment change in ELF measurements}

As documented in Table I, ELF observatories at multiple locations worldwide detected the global radiation from the sprite-producing lightning for these events. Calibrated sensors at the receiving sites have been used to calculate the vertical charge moment change of the parent lightning flashes. Comparisons of these determinations for all 14 sprite events and all receiver detections are shown in Figure 4. The values from different locations are often, though not invariably, in good agreement, supporting the capability of characterizing a source property from different distances of observation.

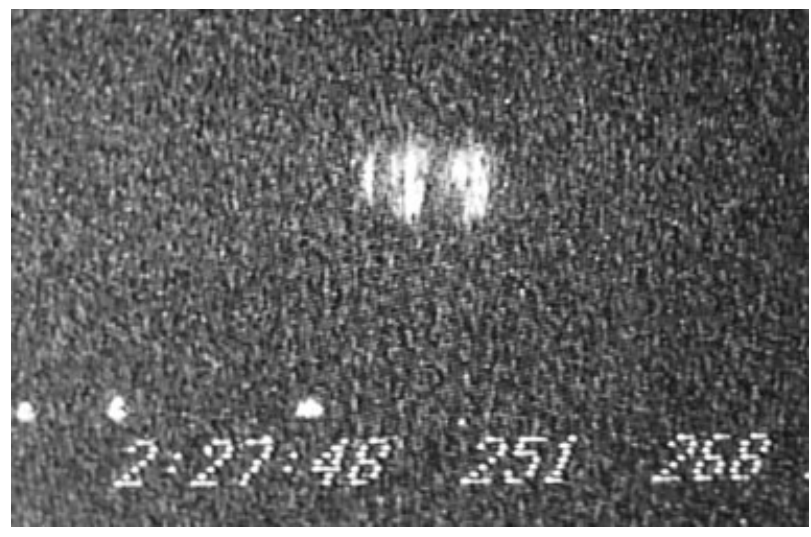

Figure 3. Sprite image recorded in Niamey, Niger for the event at 02:27:48.235-268 UT (Table I) on 21 September 2006.

For some pairs of receiving stations, the agreement in estimates for charge moment change (CMC) is even better. Figure 5(a) shows comparisons of charge moment change for simultaneously observed events from the USA (Duke University) and Hungary. Points of perfect agreement would fall on the 45 degree line. The agreement is not perfect but is still of high quality for measurements of this kind, though the measurements reported by Israel tend to be large. Figure 5(b) shows a like comparison in common events observed from Israel and from the Moshiri Observatory in Japan. Again, the agreement is excellent. In both Figures 4 and 5 it is important to note that the majority of CMC values are in excess of the threshold (500-1000 C-km) generally believed necessary for the dielectric breakdown of the mesosphere at altitudes of $\sim 75 \mathrm{~km}$ where sprites have been observed to initiate, according to the ideas initiated by C.T.R. Wilson and confirmed in other studies (Wilson, 1924; Huang et al., 1999; Hu et al., 2002; Cummer and Lyons, 2005; Hu et al., 2007).

It was frequently observed during the MIT radar campaigns in both 2006 and 2007 that MCS squall lines originating in northern Nigeria east of Niamey (as in the cases presented here) subsequently propagated westward to arrive in Niamey in the morning hours. In such cases, the energetic positive lightning flashes in these MCSs could be studied directly over the radar (Hobara et al., 2007; Williams et al., 2008b). The large and energetic positive ground flashes were invariably located in the trailing stratiform regions of the squall lines during periods of pronounced radar bright band overhead, consistent with earlier expectations (Williams, 1998).

3.4. Detailed analysis of the ELF magnetic field for an exceptional sprite-producing lightning flash on 21 September 2006

One of the strongest events appearing in Table I is the flash detected on 21 September nearly coincidently (02:27:48.248 UT) by the WWLLN and ZEUS + STARNET networks and producing the 'very bright' sprite in the camera at Niamey shown earlier in Figure 3. This event was detected by five ELF receivers, strong evidence 


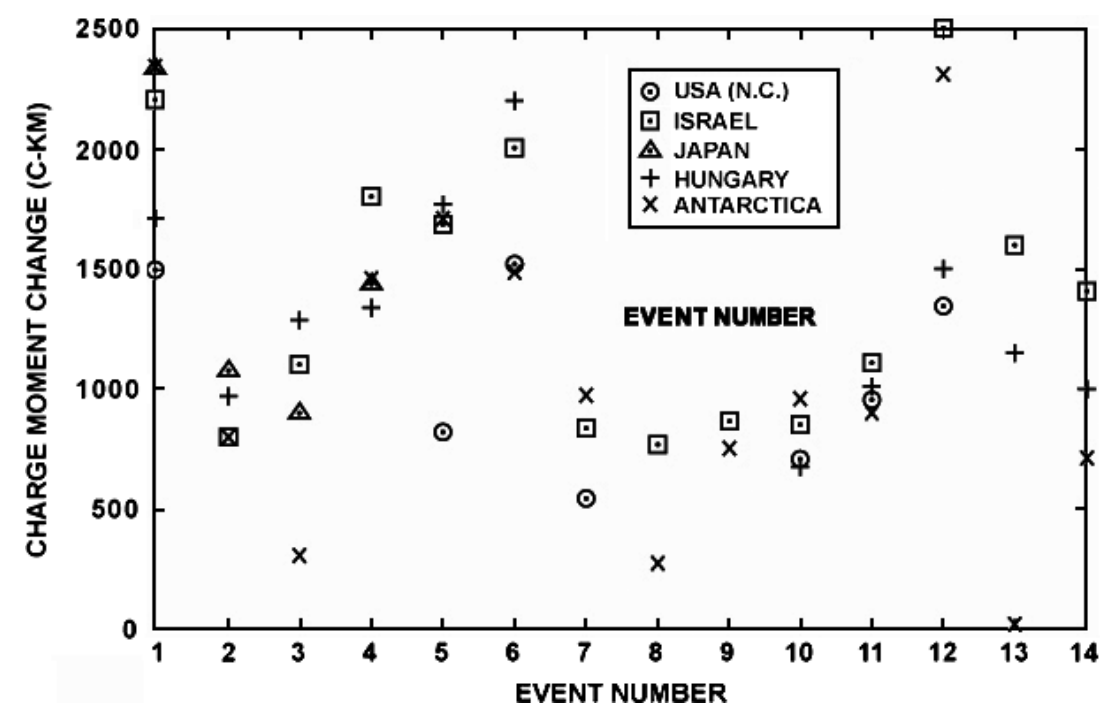

Figure 4. Comparisons of charge moments from different ELF receiving sites for all 14 events in Table I.
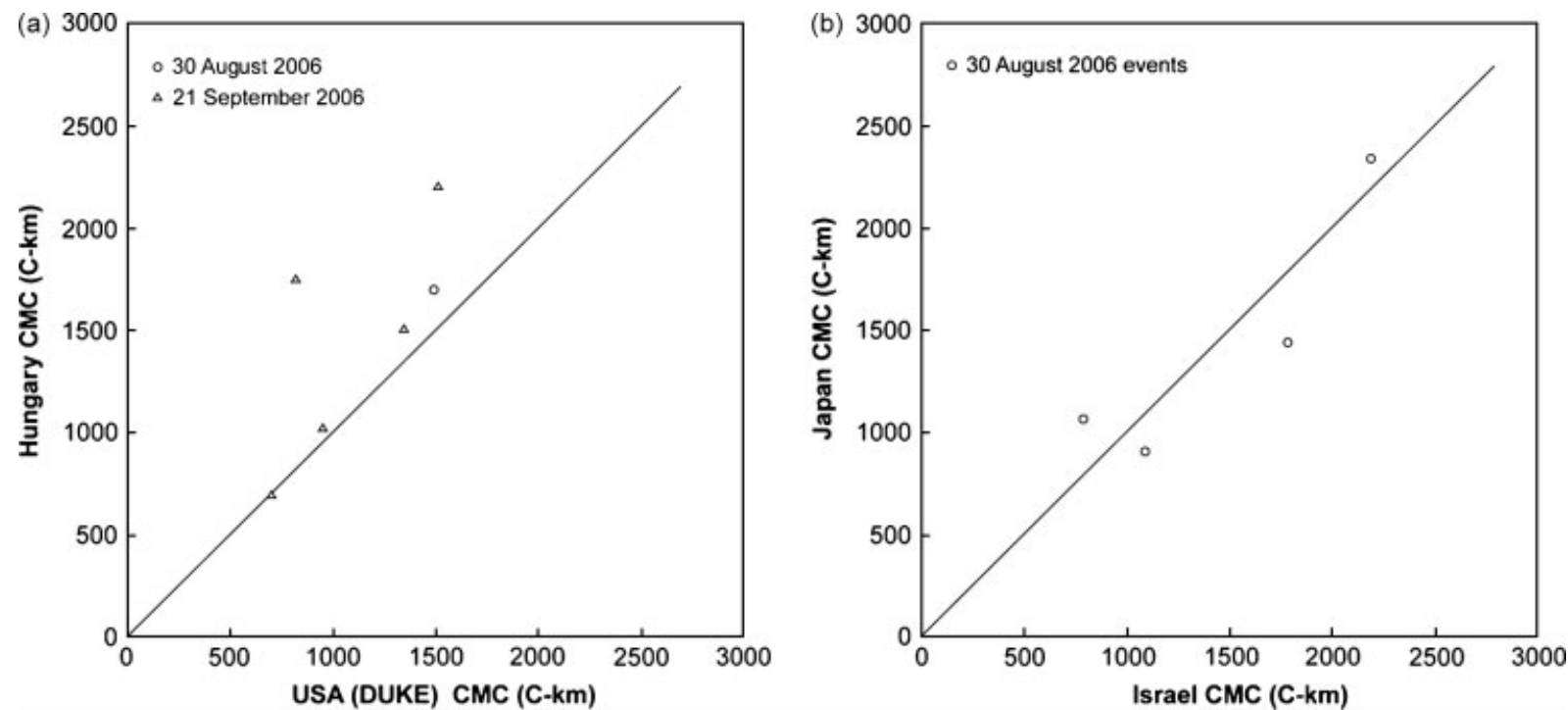

Figure 5. Pairwise comparison of estimates for vertical charge moments for common sprite lightning events recorded in (a) Hungary and the USA (Duke) on both 30 August and 21 September, 2006, and in (b) Israel and in Japan for sprite events on 30 August. The diagonal line represents the line of perfect agreement.

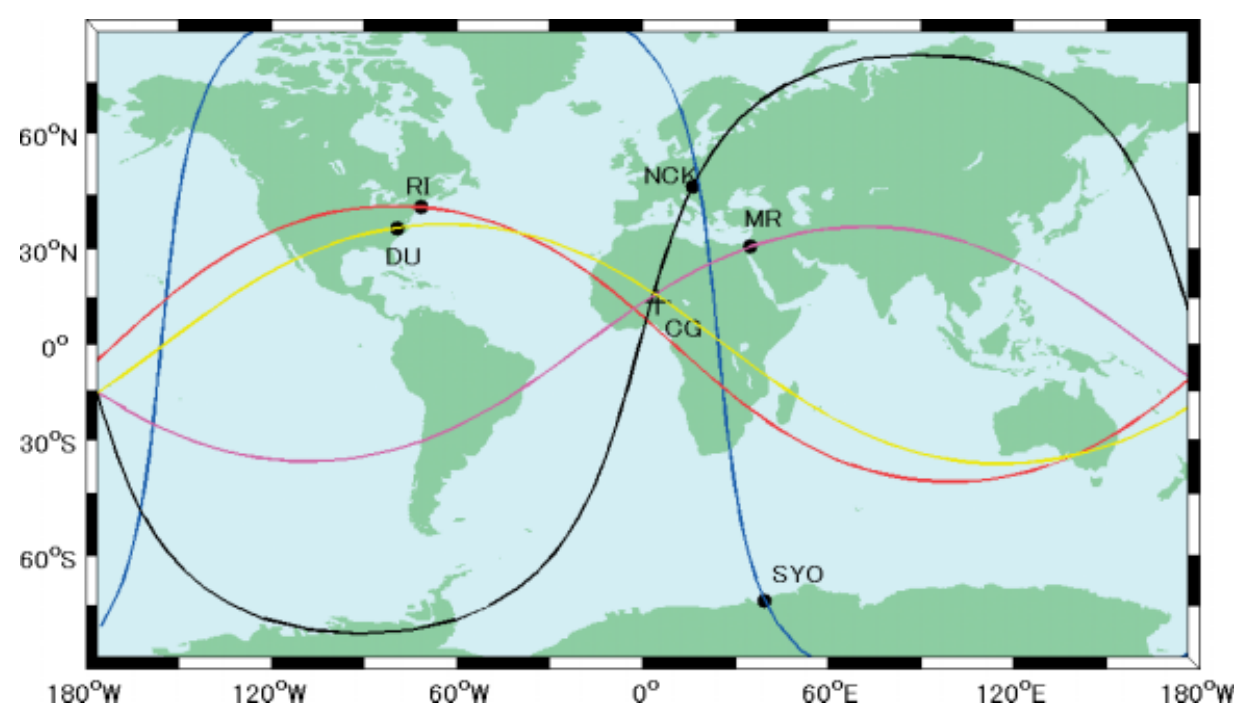

Figure 6. Great-circle paths for reception of ELF radiation for a sprite event at 02:27:48.235 UT on 21 September 2006 at five receiving stations. 

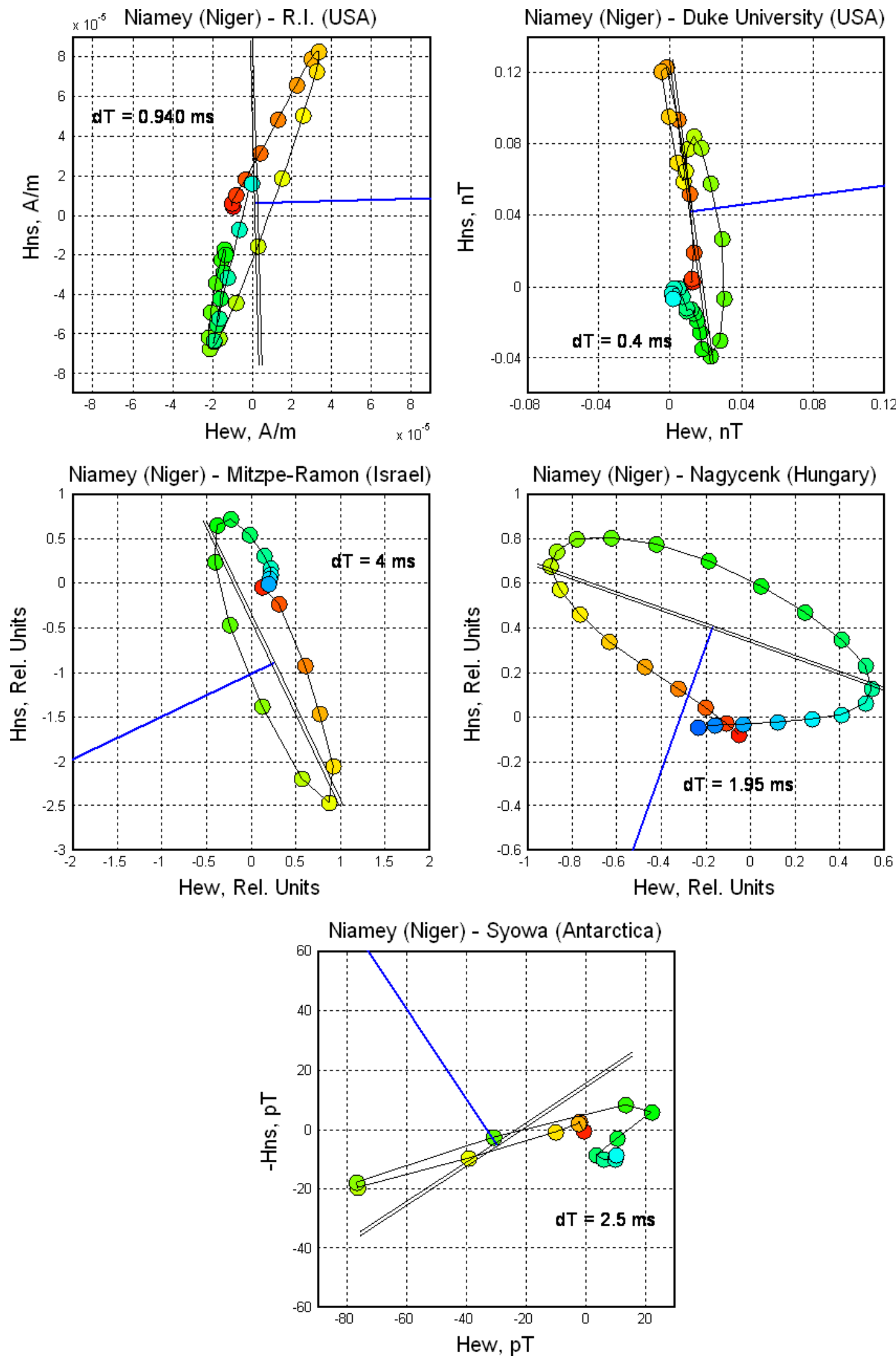

Figure 7. Observed magnetic Lissajous patterns in the horizontal magnetic field at multiple receivers for the strong lightning flash that produced the very bright sprite event at 02:27:48.235 UT on 21 September 2006. This figure is available in colour online at www.interscience.wiley.com/journal/qj 

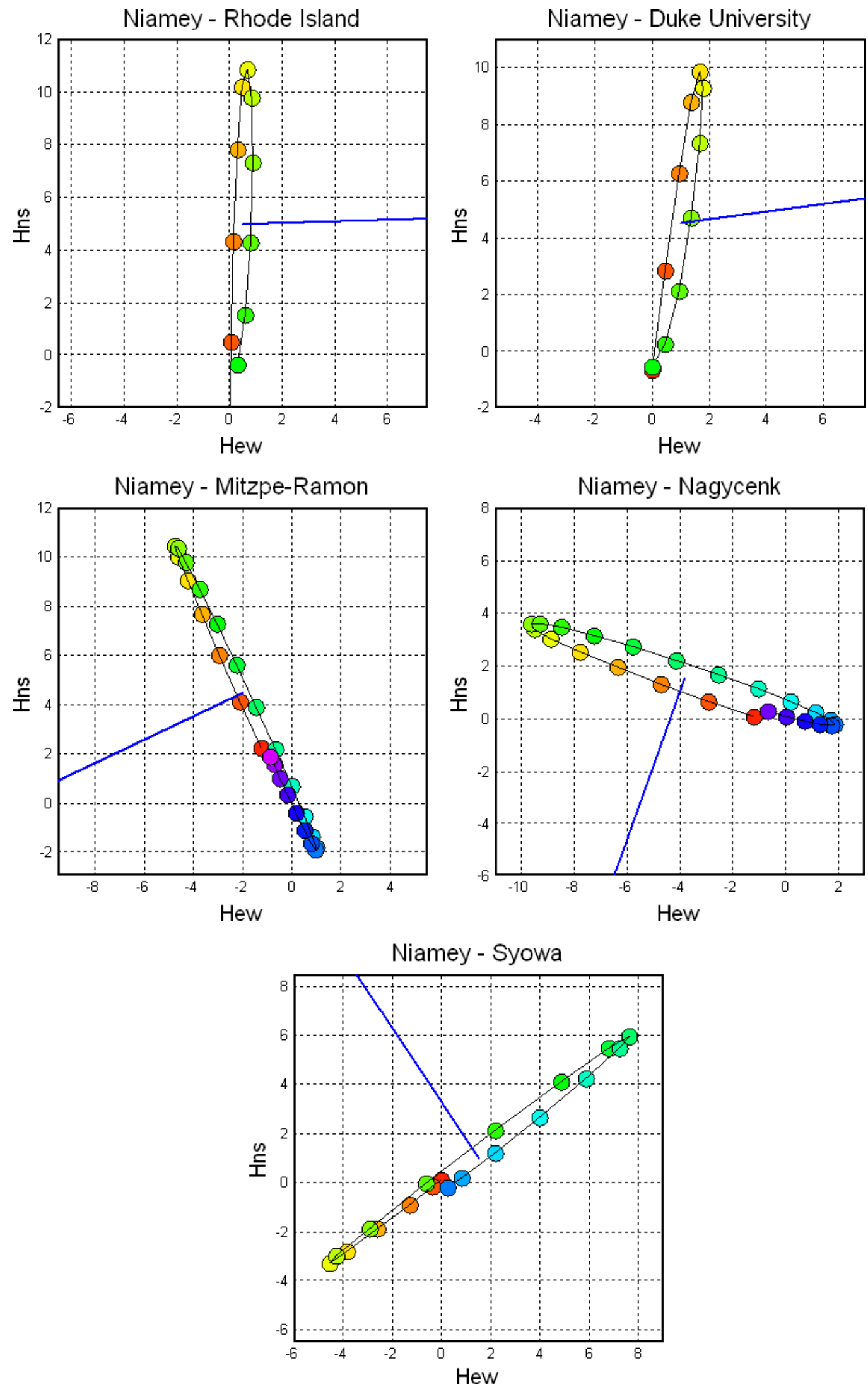

Figure 8. Simulated magnetic Lissajous patterns in the horizontal magnetic field on the basis of a transmission line model of the Earth-ionospheric cavity that includes the effect of the day-night asymmetry of the ionosphere. This figure is available in colour online at www.interscience.wiley.com/journal/qj 
in itself that this lightning flash served to 'illuminate' the entire Earth-ionosphere cavity with ELF radiation. Such a circumstance was achieved many years ago by Ogawa et al. (1967), but in the present case all receivers are equipped with a pair of orthogonal magnetic sensors. These observations enable both global triangulation, but also a detailed analysis of the magnetic polarization behaviour and its control by the asymmetry by the Earth-ionosphere cavity (see the appendix).

The global picture for this single powerful event is shown in Figure 6. This Figure shows all five greatcircle paths between receivers and lightning source, based on best estimates of magnetic direction finding for each receiving station. The intersection of great-circle paths at the VLF-determined location of the lightning source is clearly imperfect, and this result is well known at ELF (Price et al., 2002) and is caused (in part) by the recognized departures from linear polarization in the horizontal magnetic field at ELF. Figure 7 shows the observed Lissajous patterns in the horizontal magnetic field at all five receiving stations. The departure from strict linear polarization is readily apparent in all cases. The appendix presents a detailed analysis of these results with a model that includes the day-night asymmetry of the natural Earth-ionosphere waveguide and which is capable of producing simulated Lissajous patterns for the five receiving sites (Figure 8), for direct comparison with the observations in Figure 7. The strong similarity between observations and theory is evidence that the observed departure from linear polarization is caused by the day-night asymmetry.

\section{Conclusions}

The main conclusions in this study are as follows:

- Sprites have been documented for the first time from the surface of the African continent, over mesoscale convective systems in Nigeria.

- As many as six ELF stations have detected the radiation from the sprite parent lightning flashes. The polarities of all sprite events are positive. The polarity of one presumed halo event is negative.

- The simultaneous locations of lightning flashes by two VLF networks show excellent agreement in both space and time. These accurate locations provide a sound basis for further analysis of these events at ELF.

- Vertical charge moment estimates show good agreement among ELF receiving stations in most cases. The magnitudes of the charge moments are consistent with dielectric breakdown in the mesosphere as the cause for the sprites.

- Analysis of the magnetic field polarization at ELF provides good evidence that the departure from linear polarization is caused primarily by the day-night asymmetry of the Earth-ionosphere cavity.

\section{Acknowledgements}

Moustafa Boukari provided access to the Niamey control tower for video camera observations, ASECNA forecasters provided access to Meteosat imagery to plan favourable camera pointing directions, and Les Pompiers at ASECNA and the DMN meteorologist in charge gave assistance in maintaining dark conditions for observations at the airport. Nathalie Nathou, Alhassane Tidjani, Chaibou Oubandawaki, Eyal Freud, Abdou Ali, Adamou Mahamadou and Guillem Lebel provided radar support for the sprite observations. Walt Lyons contribution to this study was partially supported by the US National Science Foundation, Grant ATM-0649034 to Colorado State University and FMA Research, Inc. Jonathan D. Meyer analysed the Niger videotape records. Manos Anagnostou provided valuable suggestions on the use of the African VLF sensors.

Hartmut Höller identified events for the 30 August case on the LINET system. Jared Entin at NASA Hydrology supported the MIT radar operation in Niamey that ultimately allowed for the sprite observations reported here. Chris Thorncroft strongly supported this effort. The work on the sprite observations and attendant electromagnetic analysis was supported by the Physical Meteorology Program at NSF under Grant ATM-0734806. The contribution from Hungary was supported by grants NI 61013 and K72474 from the Hungarian Scientific Research Fund.

\section{Appendix \\ Analysis of magnetic polarization behaviour for a single sprite-related ELF lightning transient on 21 September 2006}

One of the frequently observed features of ELF transient signals emanating from strong lightning flashes is their magnetic polarization that departs markedly from linear. Figure 7 presents the magnetic Lissajous patterns (the time-domain plots of the north-south magnetic component versus the east-west one) simultaneously observed at five of the ELF stations (also listed in Table I) and generated by a strong, reliably located (by both the WWLLN and ZEUS + STARNET VLF networks) sprite event occurring east of Niamey (Niger, West Africa) at $13.46^{\circ} \mathrm{N}, 5.09^{\circ} \mathrm{E}$ on 21 September 2006 at 02:27:48.2408509 UT. The geographical locations of the source and the globally distributed observers are shown in Figure 7.

The general polarization pattern observed at all stations is a quasi-elliptical initial stage (its temporal dynamics is illustrated by the lighter-to-darker sequence of shades of grey) followed by several less structured quasi-elliptical stages of smaller amplitudes (not shown in the plots). Another characteristic feature of each observed Lissajous pattern is a more or less pronounced deviation of the major axis orientation from the direction perpendicular to the source-observer great circle, indicated in each plot by a single solid line.

The magnetic polarization behaviour was discovered in the 1970s when a new technique for the global location 
of lightning discharges based on their ELF signatures had been suggested and applied (Kemp and Jones, 1971). In particular, Kemp (1971) considered the polarization effects in the frequency domain and found that the bearing determined from the ratio of orthogonal magnetic components critically depends on frequency and had to be averaged over the equipment's frequency range to obtain a reasonable bearing accuracy. (When analysing a series of transients events generated at the Rhode Island ELF station by ground-true (optically located) sprites in northern Australia (Williams et al., 2007b), it was found that the bearing deviations estimated in the frequency and time domains are close to each other within a couple of degrees, which additionally confirms the objectivity of the findings.)

While there is a general agreement in the ELF community that the polarization behaviour is attributable to the 'desymmetrization' of the classical, spherically symmetrical model of the Earth-ionosphere waveguide (for which a linearly polarized Lissajous is predicted for a vertical lightning source), the actual hierarchy of 'desymmetrizating' factors is yet to be established. While it is widely believed that the major factor is the ionospheric anisotropy resulting in the waveguide's asymmetry due to the eccentricity of the geomagnetic dipole (Bliokh et al., 1980; Füllekrug and Sukhorukov, 1999), the theoretical simulations carried out by Nickolaenko and Hayakawa (2002) show that the geomagnetic hypothesis alone fails to interpret some well-established polarization features - in particular, the temporal change in the sense of the magnetic ellipticity of the background Schumann resonance signal (Sentman, 1989). Sentman (1987, 1989) suggested as an additional factor the changeability of the ionospheric height due to the electrodynamic difference between the day- and night-time hemispheres.

To explore the importance of the latter factor, simulations have been carried out using the two-dimensional telegraph equation (TDTE) method developed specifically for treating the irregularities and asymmetries of the ionosphere (Madden and Thompson, 1965; Kirillov and Kopeykin, 2002). This method, based on a transmission line analogy (Madden and Thompson,1965), consistently follows the idea planted by Greifinger and Greifinger (1978) to consider two complex characteristic altitudes - lower $H_{C}(f)$ and upper $H_{L}(f)$ - that present in a condensed form the frequency-dependent electrodynamic properties of two dissipation layers within the lower ionosphere (Kirillov and Kopeykin, 2002; Mushtak and Williams, 2002). In these simulations, the Greifinger et al. (2007) model of the lower characteristic altitude $H_{C}(f)$ has been exploited. The upper characteristic altitude $H_{L}(f)$, more complicated for modelling, has been derived so that the frequency dependences of the general ELF propagation parameters (the phase velocity and the attenuation factor) agree with their full-wave values computed directly from representative day- and night-time ionospheric profiles (Galejs, 1972).

The simulated polarization patterns for the five ELF observers for this sprite-producing lightning flash are presented in Figure 8. Qualitatively, the simulations demonstrate the same features as the observations - nonlinear polarization forms and deviations from the 'geometrically-optical' orientations of the major axes, clear evidence that the day/night asymmetry plays a fundamental role in the polarization effects. To understand the physical cause for these effects, it is advisable to compare the ELF expressions for the magnetic components in a spherically symmetrical (uniform) and an asymmetrical (non-uniform) model of the Earth-ionosphere waveguide.

In the uniform model, the field is expressed via the Legendre function $P_{v}$ and the characteristic altitudes as (Mushtak and Williams, 2002)

$$
H_{\phi}^{\text {SYMM }}(f, \theta) \sim \frac{I d S(f)}{H_{C}(f)} \frac{1}{\sin \{v(f) \pi\}} \frac{\mathrm{d} P_{v}\{\cos (\pi-\theta)\}}{\mathrm{d} \theta}
$$

where $I d S(f)$ is the current moment of the lightning source, $\theta$ and $\varphi$ are the observer's coordinates in a spherical system with the pole at the source's location, the eigenvalue $v(f)$ is related to the ratio of the characteristic altitudes as $v(f)\{v(f)+1\}=(k a)^{2} H_{L}(f) / H_{C}(f)$, with $k$ and $a$ denoting the wave number and the Earth's radius, respectively.

In a non-uniform waveguide, the TDTE magnetic components generated at the observer's location $O \equiv$ $\left\{a ; \Theta_{O}, \Phi_{O}\right\}$ by a lightning source located at $S \equiv$ $\left\{a ; \Theta_{S}, \Phi_{S}\right\}$ can be symbolically presented as combinations of propagation factors dependent on the source-local (denoted by $S$ ), observer-local (denoted by $O$ ) and global (put in square brackets and denoted by $S \rightarrow O$ ) electrodynamic properties of the waveguide:

$$
\begin{aligned}
& H_{\Phi}^{\mathrm{ASYMM}}(f ; S \rightarrow O) \sim I d S(f) \frac{H_{L}(f ; S)}{H_{C}(f ; S)} \\
& \times \frac{1}{H_{L}(f ; O)}\left[\frac{\partial U(f ; S \rightarrow O)}{\partial \Theta}\right], \\
& H_{\Theta}^{\mathrm{ASYMM}}(f ; S \rightarrow O) \sim I d S(f) \frac{H_{L}(f ; S)}{H_{C}(f ; S)} \\
& \quad \times \frac{1}{H_{L}(f ; O)}\left[\frac{\partial U(f ; S \rightarrow O)}{\partial \Phi}\right],
\end{aligned}
$$

where $U(f)$ is the solution of the proper twodimensional telegraph equation. (The specific form of the equation is of no principal importance in the present consideration but can be found, for instance, in the Kirillov and Kopeykin (2002) work.) Generally, expressions (2)-(3) are formulated in an arbitrary spherical system of coordinates, but when treating the day/night asymmetry, it is both natural and convenient to use a coordinate system with its pole coinciding with the sub-solar point at the Earth's surface.

The comparison of (1) with (2)-(3) shows clearly the reason for the nonlinear magnetic polarization of the observed ELF transient signals. In a hypothetical uniform waveguide, the magnetic field's (1) projections on any two orthogonal directions (including the north/south and 
east/west configuration) would be in phase with each other, and the resulting time-domain Lissajous pattern would be linear. In a real, non-uniform waveguide, the propagation of the $\Theta$-component (normal to the day-night boundary) obviously differs from that of the $\Phi$-component (tangent to the boundary), due to principal difference in the global propagation factors $\frac{\partial U(f ; S \rightarrow O)}{\partial \Phi}$ and $\frac{\partial U(f ; S \rightarrow O)}{\partial \Theta}$, respectively. As a result, there is always a phase - and, generally, an amplitude - difference between these components (resulting in a nonlinear time-domain polarization) that would be transferred to any other pair of orthogonal antennas, including the north/south and east/west configuration. (Of course, there are special scenarios - with one of the components being negligible in comparison with the other - when the nonlinear polarization would degenerate into a linear one.) The same factor is responsible for the deviation of the polarization ellipse's orientation from the 'geometryoptical' one; a more detailed insight on this effect can be found in Williams et al. (2007b, 2008a) where sprite-lightning-generated signals from a reliably located Australian storm are monitored, along with the temporal dynamics of their polarization features, for about four hours.

Despite the qualitative agreement between theory and experiment shown here, both the ellipticities, and to a lesser measure the deviations from 'geometricallyoptical' orientations of the simulated patterns, are generally less pronounced than the observed ones. This circumstance suggests a larger contrast between the dayand night-time conditions than that assumed in the simulations. No doubt, the exploited models - and that of the upper characteristic altitude, in the first place - are yet to be carefully 'tuned', and the signals from ground-true sources (like the one considered in this section) do provide invaluable information for such an inverse problem. At the same time, both the data and especially the attendant conditions are to be critically considered. In addition to the diversity of the experimental techniques exploited at different stations, deviations are evident between features observed at pairs of closely located (in the global ELF sense) stations, i.e. in the major axis' orientation between the Rhode Island and Duke locations, and in the ellipticity between the Mitzpe-Ramon and Nagycenk stations. A more critical analysis of these observations is yet to be undertaken.

These observations and comparisons with theory provide a litmus test for considering what propagation factor - the ionospheric anisotropy or the general contrast between the day- and night-time conditions - plays the major role in the polarization behaviour. If the anisotropic factor were predominant, the polar Syowa station in Antarctica (as the one located in the most anisotropic section of the waveguide) would register the most pronounced effect. This prediction is not supported here, however. From the theoretical point of view, this finding is of little surprise; while the day/night contrast has a global hemispherical scale, the strongly pronounced
ELF anisotropic effect (that depends only on the vertical projection of the geomagnetic field) is confined to the comparatively close proximity $\left(10^{\circ}\right.$ to $\left.20^{\circ}\right)$ of the pole. Nevertheless, this preliminary consideration does not exclude the further exploration of the geomagnetic factor in future research.

\section{References}

Ando Y, maltsev P, Sukhynyuk A, Goto T, Yamauchi T, Hobara Y, Sekiguchi M, Ikegami Y, Sera M, Korepanov V, Hayakawa M. 2005. New ELF observation system at Moshiri, Japan and assessments of acquired data. J. Atmos. Electr. 25: 29-39.

Betz H-D, Schmidt K, Oettinger P, Wirz M. 2004. Lightning detection with 3-D discrimination of intracloud and cloud-to-ground discharges. Geophys. Res. Lett. 31: L11108, DOI:10.1029/2004GL019821.

Bliokh PV, Nickolaenko AP, Filippov YF. 1980. Schumann resonances in the Earth-ionosphere cavity. Peter Peregrinus: Stevenage.

Boccippio DJ, Williams ER, Heckman SJ, Lyons WA, Baker IT, Boldi R. 1995. Sprites, ELF transients, and positive ground strokes. Science 269: 1088-1091.

Boeck WL, Vaughan Jr OH, Blakeslee RJ, Vonnegut B, Brook M, McKune J. 1995. Observations of lightning in the stratosphere. J. Geophys. Res. 100: 1465-1475.

Chen AB, Kuo C-L, Lee Y-J, Su H-T, Hsu R-R, Chern J-L, Frey HU, Mende SB, Takahashi Y, Fukunishi H, Chang Y-S, Liu T-Y, Lee L-C. 2008. Global distributions and occurrence rates of transient luminous events. J. Geophys. Res. 113: A08306, DOI:10.1029/2008JA013101.

Christian HJ, Blakeslee RJ, Boccippio DJ, Boeck WL, Buechler DE, Driscoll KT, Goodman SJ, Hall JM, Koshak WJ, Mach DM, Stewart MF. 2003. Global frequency and distribution of lightning as observed from space by the Optical Transient Detector. J. Geophys. Res. 108: 4005, DOI:10.1029/2002JD002347.

Chronis T, Anagnostou EN. 2003. Error analysis for a long-range lightning monitoring network of ground-based receivers in Europe. J. Geophys. Res. Atmos. 108(D24): 4779.

Chronis T, Anagnostou E. 2006. Evaluation of a long-range lightning detection network with receivers in Europe and Africa. IEEE T. Geosci. Remote 44: 1504-1510.

Cummer SA, Inan US. 1997. Measurement of charge transfer in spriteproducing lightning using ELF radio atmospherics. Geophys. Res. Lett. 24: $1731-1734$

Cummer SA, Inan US. 2000. Modeling ELF radio atmospheric propagation and extracting lightning currents from ELF observations. Radio Sci. 35: 385-394.

Cummer SA, Lyons WA. 2005. Implications of lightning charge moment changes for sprite initiation. J. Geophys. Res. 110: A04304, DOI:10.1029.2004JA010812.

Dowden RL, Holzworth RH, Rodger CJ, Lichtenberger J, Thomson NR, Jacobson AR, Lay E, Brundell JB, Lyons TJ, O'Keefe S, Kawasaki Z, Price C, Prior V, Ortega P, Weinman J, Mikhailov Y, Veliz O, Qie X, Burns G, Collier A, Pinto Jr O, Diaz R, Adamo C, Williams ER, Kumar S, Raga GB, Rosado JM, Avila EE, Cliverd MA, Ulich T, Gorham P, Shanahan TJG, Osipowicz T, Cook G, Zhao Y. 2008. World-wide lightning location using VLF propagation in the Earth-ionosphere waveguide. IEEE Antennas and Propagation Mag. 50: 40-60.

Füllekrug M, Price C. 2002. Estimation of sprite occurrences in central Africa. Meteorol. Z. 11: 99-104.

Füllekrug M, Sukhorukov AI. 1999. The contribution of anisotropic conductivity in the ionosphere to lightning flash bearing deviations in the ELF/ULF range. Geophys. Res. Lett. 26: 1109-1112.

Galejs J. 1972. Terrestrial propagation of long electromagnetic waves. Pergamon Press: Oxford-New York-Toronto-Sydney-Braunschweig. Greifinger C, Greifinger P. 1978. Approximate method for determining ELF eigenvalues in the Earth-ionosphere waveguide. Radio Sci. 13: $831-837$.

Greifinger PS, Mushtak VC, Williams ER. 2007. On modeling the lower characteristic ELF altitude from aeronomical data. Radio Sci. 42: RS2S12, DOI:10.1029/2006RS003500.

Heckman SJ, Williams ER, Boldi R. 1998. Total global lightning inferred from Schumann resonance measurements. J. Geophys. Res. 103: $31775-31779$. 
Hobara Y, Iwasaki N, Hayashida T, Tsuchiya N, Williams ER, Sera M, Ikegami Y, Hayakawa M. 2000. New ELF observation site in Moshiri, Hokkaido, Japan and the results of preliminary data analysis. J. Atm. Electr. 20: 99-109.

Hobara Y, Iwasaki N, Hayashida T, Hayakawa M, Ohta K, Fukunishi H. 2001. Interrelation between ELF transients and ionospheric disturbances in association with sprites and elves. Geophys. Res. Lett. 28: 935-938.

Hobara Y, Hayakawa M, Williams ER, Boldi R, Downes E. 2006. Location and electrical properties of sprite-producing lightning from a single ELF site. Pp 211-236 in Sprites, elves and intense lightning discharges, Füllekrug M, Mareev EA, Rycroft MJ (eds). NATO Science Series, II. Mathematics, Physics and Chemistry 225. Springer.

Hobara Y, Williams ER, Boldi R, Sátori G, Bór J, Lyons WA, Nelson T, Hayakawa M, Price C, Greenburg E, Nathou N, Russell B. 2007. 'Mesoscale lightning in West African squall lines and its global detection with ELF measurements.' Pp 589-592 in Proceedings of the $13^{\text {th }}$ International Conference on Atmospheric Electricity, Vol. II, ICAE/IAMAS/IUGG, Beijing, China, 13-17 August, 2007.

$\mathrm{Hu}$ W, Cummer SA, Lyons WA, Nelson TE. 2002. Lightning charge moment changes for the initiation of sprites. Geophys. Res. Lett. 29: 1279, DOI:10.1029/2001GL014593.

$\mathrm{Hu}$ W, Cummer SA, Lyons WA. 2007. Testing sprite initiation theory using lightning measurements and modeled electromagnetic fields. J. Geophys. Res. 112: D13115, DOI:10.1029/2006JD007939.

Huang E, Williams ER, Boldi R, Heckman S, Lyons WA, Taylor M, Nelson T, Wong C. 1999. Criteria for sprites and elves based on Schumann resonance observations. J. Geophys. Res. 104: $16943-16964$

Jacobson AR, Holzworth R, Harlin J, Dowden R, Lay E. 2006. Performance assessment of the World Wide Lightning Location Network (WWLLN), using the Los Alamos Sferic Array (LASA) as ground truth. J. Atmos. Oceanic Technol. 23: 1082-1092.

Kemp DT. 1971. The global location of large lightning discharges from single station observations of ELF disturbances in the Earth-ionosphere cavity. J. Atmos. Terr. Phys. 33: 919-927.

Kemp DT, Jones DL. 1971. A new technique for the analysis of transient ELF electromagnetic disturbances within the Earth-ionosphere cavity. J. Atmos. Terr. Phys. 33: 567-572.

Kirillov VV, Kopeykin VN. 2002. Solving a two-dimensional telegraph equation with anisotropic parameters. Radiophysics and Quantum Electronics 45: 929-941.

Kotroni V, Lagouvardos K. 2008. Lightning occurrence in relation with elevation, terrain slope, and vegetation cover in the Mediterranean. J. Geophys. Res. 113: D21118, DOI:10.1029/2008JD010605.

Lagouvardos K; Kotroni V, Betz H, Schmidt K. 2008. 'Assessment of the ZEUS lightning detection network over Europe by comparison with lightning data from LINET.' 10th EGU Plinius Conference on Mediterranean Storms, Nicosia, Cyprus, 22-24 September 2008.

Laing AG, Fritsch JM. 1993. Mesoscale convective complexes in Africa. Mon. Weather Rev. 121: 2254-2263.

Lay EH, Jacobson AR, Holzworth RH, Rodger CJ, Dowden RL. 2007. Local time variation in land/ocean lightning flash density as measured by the World Wide Lightning Location Network. J. Geophys. Res. 112: D13111, DOI:10.1029/2006JD007944.

Lyons WA. 1996. Sprite observations above the U.S. High Plains in relation to their parent thunderstorm systems. J. Geophys. Res. 101: 29641-29652.

Lyons WA. 2006. The meteorology of transient luminous events - An introduction and overview. $\mathrm{Pp} \mathrm{19-56} \mathrm{in} \mathrm{Sprites,} \mathrm{elves} \mathrm{and} \mathrm{intense}$ lightning discharges, Füllekrug M, Mareev EA, Rycroft MJ (eds). NATO Science Series II (Mathematics, Physics and Chemistry), Vol. 225. Springer Publishing House.

Lyons WA, Williams ER. 1993. 'Preliminary investigations of the phenomenology of cloud-to-stratosphere lightning discharges.' In Preprints, Conference on atmospheric electricity, St. Louis, Missouri. American Meteorological Society.

Lyons WA, Nelson TE, Williams ER, Cummer SA, Stanley MA. 2003. Characteristics of sprite-producing positive cloud-to-ground lightning during the 19 July 2000 STEPS mesoscale convective systems. Mon. Weather Rev. 131: 2417-2427.

Lyons WA, Stanley MA, Meyer JD, Nelson TE, Rutledge SA, Lang TL, Cummer SA. 2009. The meteorological and electrical structure of TLE-producing convective storms. Pp 387-416 in Lightning: Principles, instruments and applications, Betz HD, Schumann U, Laroche P (eds). Springer.
Madden T, Thompson W. 1965. Low-frequency electromagnetic oscillations of the Earth-ionosphere cavity. Rev. Geophys. 3: 211-254.

Malan D. 1937. Sur les décharges orageuses dans la haute atmosphère. Academie des Sciences, 3 November session.

Miller MA, Slingo A. 2007. The ARM Mobile Facility and its first international deployment: Measuring radiation flux divergence in West Africa. Bull. Am. Meteorol. Soc. 88: 1229-1244.

Morales CA. 2001. 'Continuous thunderstorm monitoring: Retrieval of precipitation parameters from lightning observations'. Ph.D. Thesis, Department of Civil and Environmental Engineering, University of Connecticut: Storrs, CT.

Morales CA, Anagnostou E, Williams E, Kriz S. 2007. Evaluation of peak current polarity retrieved by the ZEUS long-range lightning monitoring system. IEEE Geosci. Remote S. V4: 32-36.

Morel C, Senesi S. 2002. A climatology of mesoscale convective systems over Europe using satellite infrared imagery. I Methodology. Q. J. R. Meteorol. Soc. 128: 1953-1971.

Mushtak VC, Williams ER. 2002. ELF propagation parameters for uniform models of the Earth-ionosphere waveguide. J. Atmos. Solar-Terr. Phys. 64: 1989-2001.

Nickolaenko AP, Hayakawa M. 2002. Resonances in the Earth-ionosphere cavity. Kluwer Academic Publishers: Dordrecht/Boston/London

Ogawa T, Tanaka Y, Yasuhara M, Fraser-Smith AC, Gendrin R. 1967 Worldwide simultaneity of occurrence of a Q-type ELF burst in the Schumann resonance frequency range. J. Geomagnet. Geoelec. 19: 377-384.

Price C, Asfur M, Lyons WA, Nelson T. 2002. An improved ELF/VLF method for globally geolocating sprite-producing lightning. Geophys. Res. Lett. 29: 1031, DOI:10.1029/2001GL013519.

Redelsperger J-L, Thorncroft CD, Diedhiou A, Lebel T, Parker DJ, Polcher J. 2006. African Monsoon Multidisciplinary Analysis: An international research project and field campaign. Bull. Am. Meteorol. Soc. 87: 1739-1746.

Rodger CJ, Werner SW, Brundell JB, Thomson NR, Lay EH, Holzworth RH, Dowden RL. 2006. Detection efficiency of the VLF World-Wide Lightning Location Network (WWLLN): Initial case study. Ann. Geophys. 24: 3197-3214.

Sátori G, Szendröi J, Verö J. 1996. Monitoring Schumann resonances. I: Methodology. J. Atmos. Terr. Phys. 58: 1475-1481.

Sentman DD. 1987. Magnetic elliptical polarization of Schumann resonances. Radio Sci. 22: 595-606.

Sentman DD. 1989. Detection of elliptical polarization and mode splitting in discrete Schumann resonance excitations. J. Atmos. Terr. Phys. 51: 507-519.

Taylor MJ, Bailey MA, Pautet PD, Cummer SA, Jaugey N, Thomas JN, Solorzano NN, Sao Sabbas F, Holzworth RH, Pinto O, Schuch NJ. 2008. Rare measurements of a sprite with halo event driven by a negative lightning discharge over Argentina. Geophys. Res. Lett. 35 : L14812, DOI:10.1029/2008GL033984.

Tomasini M, Lafore J-P, Piriou C, Roca R, Ramage K, Laurent H, Morel C, Senesi S. 2006. 'Atlas on a climatology of West African mesoscale convective systems.' AMMA-EU report Du 2/1/3/a.

Toracinta ER, Zipser EJ. 2001. Lightning and SSM/I-ice-scattering mesoscale convective systems in the global tropics. J. Appl. Meteorol. 40: 983-1002.

Vaughan Jr OH, Blakeslee R, Boeck WL, Vonnegut B, Brook M, McKune Jr J. 1992. A cloud-to-space lightning as recorded by the Space Shuttle payload-bay TV cameras. Mon. Weather Rev. 120: 1459-1461.

Williams ER. 1998. The positive charge reservoir for sprite-producing lightning. J. Atmos. Solar-Terr. Phys. 60: 689-692.

Williams ER. 2001. Sprites, elves, and glow discharge tubes. Phys Today 54: 41-47.

Williams ER, Sátori G. 2004. Lightning, thermodynamic and hydrological comparison of the two tropical continental chimneys. J. Atmos. Solar-Terr. Phys. 66: 1213-1231.

Williams ER, Yair Y. 2006. The microphysical and electrical properties of sprite-producing thunderstorms. Pp 57-84 in Sprites, elves and intense lightning discharges, Füllekrug M, Mareev EA, Rycroft MJ (eds). NATO Science Series, II. Mathematics, Physics and Chemistry 225. Springer: Dordrecht.

Williams ER, Downes E, Boldi R, Lyons WA, Heckman S. 2007a. Polarity asymmetry of sprite-producing lightning: A paradox? Radio Sci. 42: RS2S17, DOI:10.1029/2006RS003488.

Williams ER, Mushtak VC, Boldi R, Dowden RL, Kawasaki ZI. 2007b. Sprite lightning heard round the world by 
Schumann resonance methods. Radio Sci. 42: RS2S20, DOI:10.1029/2006RS003498.

Williams ER, Mushtak VC, Boldi R, Dowden RL, Kawasaki Z-I

2008a. Reply to comment by A. P. Nickolaenko and M. Hayakawa on 'Sprite lightning heard round the world by Schumann resonance methods'. Radio Sci. 43: RS3009, DOI:10.1029/2007RS003778.

Williams ER, Hobara Y, Boldi R, Lyons WA, Nelson T, Russell B, Mushtak VC, Sátori G, Bór J, Cummer S, Price C, Greenberg E, Takahashi Y, Holzworth R. 2008b. 'Meteorological origin of Q- bursts and sprites over West Africa.' Invited presentation at the AMS Annual Meeting, New Orleans, January 2008.

Wilson CTR. 1924. The electric field of a thundercloud and some of its effects. Proc. Phys. Soc. London 37: 32D-37D.

Yair Y, Israelevich P, Devir AD, Moalem M, Price C, Joseph JH, Levin Z, Ziv B, Sternlieb A, Teller A. 2004. New observations of sprites from the space shuttle. J. Geophys. Res. 109: D15201, DOI:10.1029/2003JD004497. 